\title{
AVALIAÇÃO DA ACESSIBILIDADE EFETIVA NA BIBLIOTECA CENTRAL DA UNIVERSIDADE CATÓLICA DE PERNAMBUCO
}

\author{
MORAES, Ramana Rodrigues (1); \\ BAPTISTA, Arthur Henrique Neves 2)
}

(1) Universidade Católica de Pernambuco, Graduanda em Arquitetura e Urbanismo e-mail:ramanarodriguesm@gmail.com

(1) Universidade Católica de Pernambuco, Doutor em Desenvolvimento Urbano e-mail:arthurbap@gmail.com

\begin{abstract}
RESUMO
Este trabalho utiliza procedimentos metodológicos da Teoria da Acessibilidade Efetiva para verificação das condições de Acessibilidade nas estruturas da Biblioteca Central da Universidade Católica de Pernambuco. Os procedimentos relacionam a pessoa, o deslocamento, o acionamento, a orientação e a comunicação, para avaliar a acessibilidade do ambiente construído com critérios ergonômicos. Os resultados contribuem para futuras propostas e intervenções visando um Desenho Universal.
\end{abstract}

Palavras chave: Acessibilidade Efetiva; Biblioteca Central; Desenho Universal.

\begin{abstract}
This work uses methodological procedures of the Theory of Effective Accessibility to verify the conditions of Accessibility in the structures of the Central Library of the Catholic University of Pernambuco. The procedures relate the person, the displacement, the actuation, the orientation and the communication, to evaluate the accessibility of the built environment with ergonomic standards. The results contribute to future proposals and interventions that aims a Universal Design.

Key words: Effective Accessibility; Central Library; Universal Design.
\end{abstract}

\section{INTRODUÇÃO}

O trabalho visa explicar e verificar o fenômeno da Acessibilidade Efetiva na Biblioteca Central da Universidade Católica de Pernambuco. São graficamente mostrados seu deslocamento, acionamento, orientação e comunicação e como cada item se comporta perante três tipos de pessoas: uma pessoa com deficiência física usuária de cadeira de rodas, uma pessoa sem deficiência e uma pessoa com deficiência visual total.

O estudo da acessibilidade efetiva se distingue dos demais estudos sobre acessibilidade por, ao invés de verificar o cumprimento ou não da normativa, analisa as possibilidades de realização da tarefa, numa abordagem ergonômica, avaliando a acessibilidade efetiva vivenciada pela pessoa. $O$ entendimento é que a Acessibilidade Efetiva só pode ser conhecida se for compreendida como resultado das interações entre: [1] as aptidões de um elemento Acessante; [2] as exigências das atividades realizadas; [3] a configuração do elemento Acessado; [4] e o contexto circunstancial em que este se encontra; [5] todo sob a influência de fatores de conveniência. Estes elementos conformam um Sistema Acessante - Tarefa - 


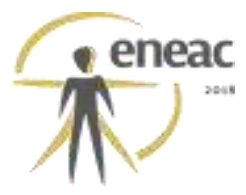

Acessado (SATA) que se altera a cada mudança circunstancial e recebe a influência externa de conveniências atrativas ou repulsivas (BAPTISTA, 2010).

\section{CONCEITUAÇÃO TEÓRICA}

A Teoria da Acessibilidade Efetiva (TAE) tem uma base conceitual formada por três pilares: [1] a ergonomia, que se apropria de técnicas e métodos visando ao ajuste da demanda do trabalho à capacidade das pessoas; [2] a filosofia e princípios do design universal, ao entender que projetos amigáveis, atrativos e sem barreiras podem ser utilizados por ampla gama de usuários, sem segregação; [3] e a Classificação Internacional de Funcionalidade Incapacidade e Saúde da Organização Mundial e Saúde (OMS), que compreende que a funcionalidade de uma pessoa só pode ser avaliada considerando-se as distintas atividades e participações e sob a influência de fatores ambientais (BAPTISTA, 2010).

\section{PROCEDIMENTOS METODOLÓGICOS}

A partir dos critérios da TAE e da configuração do SATA foram considerados:

- 03 Sistemas Acessantes - [01] - uma pessoa jovem sem deficiências aparentes; [02]

- uma pessoa com deficiência física usuária de cadeira de rodas, possuindo limitação física; [03] - uma pessoa com deficiência visual total, possuindo limitação sensorial.

- 02 Tipos de Tarefas x Contexto - [1] Positivo - Acesso e procura sem pressa e dia/horário considerado calmo; [2] Negativo - Acesso e procura com pressa num dia/horário considerado tumultuado.

- Os 03 pavimentos com seus respectivos ambientes do edifício da biblioteca

A partir dos três Sistemas Acessantes, das duas tarefas num dado contexto, e dos três pavimentos foram elaborados 18 mapas diferentes, onde é possível verificar através das cores os níveis de Acessibilidade Efetiva de cada um dos elementos (ver Figura 01 em Anexo).

\section{ANÁLISE E CONSIDERAÇÕES}

Nesta primeira etapa da pesquisa a análise foi feita com base na percepção subjetiva do pesquisador. Numa segunda etapa a avaliação será repetida com critérios mais rígidos. Foi avaliado conjuntamente todas as interações, nota-se que o sistema acessante 01 possui maior nível de Acessibilidade Efetiva por não apresentar maiores dificuldades de locomoção, já o sistema acessante 02 e 03, que dispõe de limitações físicas e visuais respectivamente possuem mais dificuldades de circulação, por diversos motivos. A partir da análise, foi possível verificar que uma pessoa sem deficiência consegue circular livremente mesmo em um contexto negativo, diferente de um cadeirante que necessita de espaço adequado para fazer seus movimentos. Já a pessoa com deficiência visual possui as mesmas barreiras que uma pessoa sem deficiência, sendo mais sensível à obstáculos aéreos, espaços muito grandes e à falta de comunicação especial, necessitando de um pouco mais de atenção.

O trabalho está avaliando as condições de Acessibilidade da Biblioteca Central da Universidade Católica de Pernambuco, tendo como base a TAE e seus procedimentos metodológicos de caráter ergonômico e que visam um Desenho Universal. Após a análise do ambiente construído e a apreciação de cada interação isoladamente de acordo com o Espectro de cores, foi possível fazer uma apreciação 


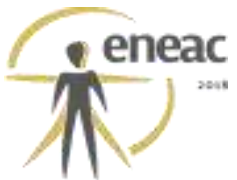

em conjunto dos níveis oferecidos pela Biblioteca Central. Espera-se com o prosseguimento desta pesquisa contribuir para que a Biblioteca possua um acesso mais universal.

\section{REFERÊNCIAS BIBLIOGRÁFICAS}

BAPTISTA, A. H. N. Proposição da Teoria da Acessibilidade Efetiva com plano de verificação para estruturas de circulação de pedestre. Tese (Doutorado em

Desenvolvimento Urbano). Universidade Federal de Pernambuco, Recife: o autor, 2010.

\section{ANEXOS}

Figura 1 - Mapeamento da Acessibilidade Efetiva nas 18 interações.

\begin{tabular}{|c|c|c|}
\hline 造 & प्र & $\begin{array}{l}8 \\
8 \\
8 \\
8\end{array}$ \\
\hline & ชิ & \\
\hline 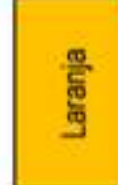 & $\begin{array}{l}\text { 웜 } \\
\text { yิ⿺ } \\
\text { 동 }\end{array}$ & 음 \\
\hline $\begin{array}{l}\text { 㔄 } \\
\text { 家 }\end{array}$ & 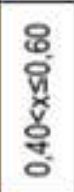 & 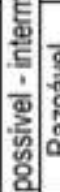 \\
\hline 帝 & 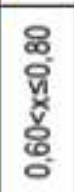 & : \\
\hline 5 & $\begin{array}{l}8 \\
\frac{8}{y} \\
\frac{1}{x} \\
\text { \&. } \\
0\end{array}$ & \\
\hline 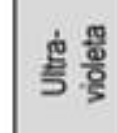 & $\frac{8}{\frac{\pi}{x}}$ & \\
\hline 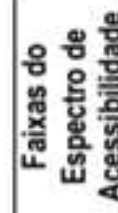 & 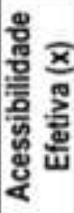 & \\
\hline
\end{tabular}
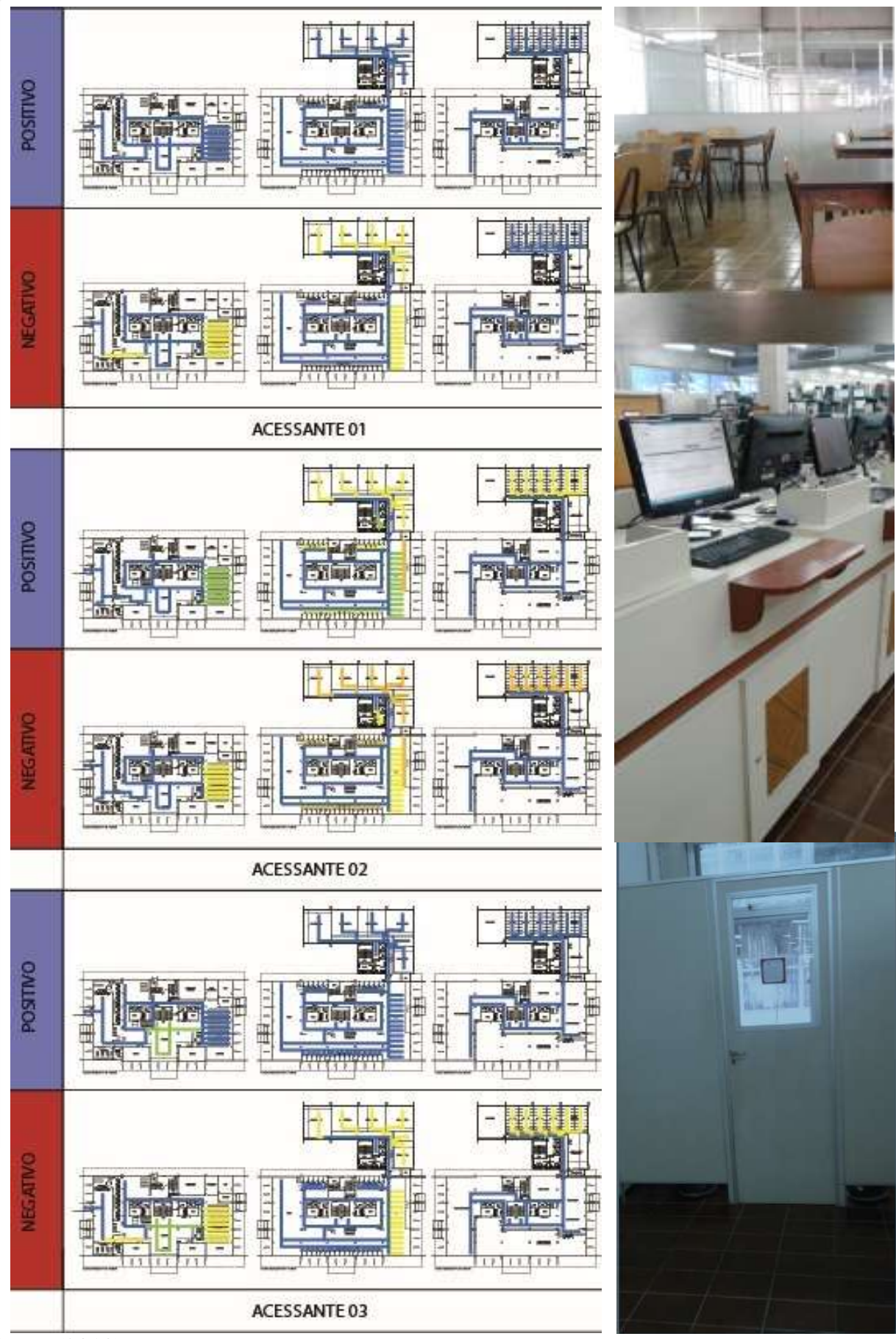